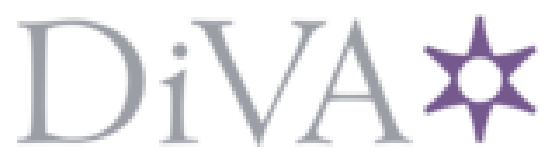

http://www.diva-portal.org

This is the published version of a paper published in Frontiers in Cellular and Infection Microbiology.

Citation for the original published paper (version of record):

Francis, M. (2013)

The pathogenic Yersiniae: advances in the understanding of physiology and virulence.

Frontiers in Cellular and Infection Microbiology, 3(51): 1-2

http://dx.doi.org/10.3389/fcimb.2013.00051

Access to the published version may require subscription.

N.B. When citing this work, cite the original published paper.

Permanent link to this version:

http://urn.kb.se/resolve?urn=urn:nbn:se:umu:diva-80465 


\title{
The pathogenic Yersiniae-advances in the understanding of physiology and virulence
}

\author{
Matthew S. Francis* \\ Department of Molecular Biology and Umeå Centre for Microbial Research, Umeå University, Umeå, Sweden \\ *Correspondence: matthew.francis@molbiol.umu.se \\ Edited by: \\ Yousef A. Kwaik, University of Louisville School of Medicine, USA
}

Keywords: Yersinia, cellular physiology, metabolism, pathogenicity, host-pathogen interactions, immunity, host responses

Of the $\sim 16$ Yersinia species, only Y. pestis, Y. pseudotuberculosis, and $Y$. enterocolitica are pathogenic to humans (Koornhof et al., 1999; Smego et al., 1999). The zoonotic obligate pathogen Y. pestis is the causal agent of plague, a systemic disease that is usually fatal if left untreated. Free-living Y. enterocolitica and Y. pseudotuberculosis are the agents of yersiniosis, a rarely systemic gastrointestinal disease. At the forefront of Yersinia research are studies of host cell contact, protein secretion, pathogenesis, immunity and the host response, nutrient sensing and sequestration and the control of gene expression. In this special research topic on the pathogenic Yersiniae is a compilation of reviews and research articles that highlight current knowledge and new developments in these areas of Yersinia pathophysiology.

\section{BACTERIA-HOST CELL CONTACT}

Yersinia is armored with diverse membrane anchored surface adhesins that each contribute to pathogen-host interactions. Mikula et al. (2013) explore the structure and virulence function of the most prominent of these adhesins. They describe salient roles of select adhesins in intestinal pathogenesis by enteric Yersinia and give insight on how altered adhesive potential through specific gene loss or gain may have contributed to Y. pestis lifestyle changes. Complementing this is Kolodziejek et al. (2012) that dissects specific physical properties and functional contributions of the esoteric Ail adhesin to Y. pestis infections.

\section{PROTEIN SECRETION}

The Ysc-Yop type III secretion system (T3SS) is encoded on a virulence plasmid common to all human pathogenic Yersinia (Cornelis et al., 1998). This injectisome is believed to provide a conduit through which Yop effector toxins can be delivered from the bacterial cytoplasm into the eukaryotic cell cytosol in one step or two (Edgren et al., 2012). Dewoody et al. (2013) provide insight into the regulatory mechanisms controlling injectisome assembly and the hierarchal coordination of substrate secretion. One important regulatory mechanism is the YopN secretion plug, and this is the focus of a study by Joseph and Plano (2013) that demonstrate a stretch of sequence within YopN - corresponding to a site for chaperone binding - is also required for environmental control of Ysc-Yop secretion.

While Yersinia pathogenicity is correlated mostly to the plasmid encoded Ysc-Yop T3SS, von Tils et al. (2012) discuss the impact of type II secretion systems (T2SS) - found in the genomes of all pathogenic and non-pathogenic Yersinia alike-to bacterial survival in the environment and in the host.

\section{IMMUNITY AND PATHOGENSIS}

Of the six known Ysc-Yop T3SS translocated effector toxins, YopM function remains enigmatic. As a consequence, Uittenbogaard et al. (2012) performed an exhaustive characterization of early host cell responsiveness to YopM of $Y$. pestis. This revealed exciting new molecular pathways potentially targeted by YopM. Early host responsiveness was also the focus of Vagima et al. (2012), which presents a role for bone marrow derived cells in the early sensing of lung infections by $Y$. pestis. Moreover, recognizing that cell death is a critical attribute of host immunity and microbial pathogenicity, Philip and Brodsky (2012) report on how cell death programs serve as both a Yersinia virulence strategy via T3SS-translocated YopJ effector function, as well as an elicitor of innate and adaptive immune responses designed to counteract Yersinia infections.

Critical in the evolution of $Y$. pestis has been the acquisition of the gene pla encoding an omptin-like outer membrane plasminogen activator protease (Pla). Korhonen et al. (2013) discuss this by summarizing features of controlled Pla protease activation, and its subsequent complex repertoire of interactions with host coagulation and fibrinolysis factors.

\section{NUTRIENT SENSING AND SEQUESTRATION}

A growing theme in infection biology research is the link between carbon metabolism and virulence (Poncet et al., 2009; Rohmer et al., 2011). Heroven et al. (2012) explore this concept in Yersinia pathogenicity using global omics-based profiling. They establish that the carbon storage regulator (Csr) system is controlled by the cAMP receptor protein (Crp), and together customize virulence gene expression according to the prevailing nutrient availability during Yersinia infections.

A critical nutrient for growth of all life forms is iron. Rakin et al. (2012) describe an array of independent siderophoremediated iron sequestration systems encoded by $Y$. pestis and the enteric Yersinia. They propose that by acquiring multiple alternative endogenous siderophore systems with unique physiological properties, Yersinia has gained the capacity to adapt and thrive in diverse environmental niches.

\section{GENE EXPRESSION CONTROL}

Defining roles for small non-coding RNAs (ncRNAs) in regulation of gene expression dominates the infection biology landscape. Schiano and Lathem (2012) provide examples of small ncRNAs and various other post-transcriptional mechanisms in the regulation of virulence gene expression in Yersinia. They even propose that subtle sequence and/or regulatory differences found 
in certain small ncRNAs could account for some of the acquired lifestyle changes of $Y$. pestis.

Conditions that threaten the integrity of the bacterial envelope are collectively termed extracytoplasmic stresses (ECS). Bacteria encode distinct regulatory pathways designed to maintain bacterial envelope integrity when challenged by ECS. Flores-Kim and Darwin (2012) describe how these ECS responsive pathways are also important for the control of Yersinia virulence determinants; particularly those embedded in the bacterial envelope such as integral membrane-spanning T3SSs and the well-known surface adhesin invasin. The environmental control of invasin gene expression in Y. enterocolitica is further explored by Brzostkowska et al. (2012). They demonstrate that $\mathrm{OmpR}$, a response regulator of the EnvZ/OmpR two-component regulatory system, binds the inv promoter to directly negatively influence invasin expression.

\section{REFERENCES}

Brzostkowska, M., Raczkowska, A., and Brzostek, K. (2012). OmpR, a response regulator of the twocomponent signal transduction pathway, influences inv gene expression in Yersinia enterocolitica O9. Front. Cell. Infect. Microbiol. 2:153. doi: 10.3389/fcimb.2012.00153

Cornelis, G. R., Boland, A., Boyd, A. P., Geuijen, C., Iriarte, M., Neyt, C., et al. (1998). The virulence plasmid of Yersinia, an antihost genome. Microbiol. Mol. Biol. Rev. 62, 1315-1352.

Dewoody, R. S., Merritt, P. M., and Marketon, M. M. (2013). Regulation of the Yersinia type III secretion system: traffic control. Front. Cell. Infect. Microbiol. 3:4. doi: 10.3389/fcimb.2013.00004

Edgren, T., Forsberg, A., Rosqvist, R., and Wolf-Watz, H. (2012). Type III secretion in Yersinia: injectisome or not? PLoS Pathog. 8:e1002669. doi: 10.1371/journal.ppat.1002669

Flores-Kim, J., and Darwin, A. J. (2012). Links between type III secretion and extracytoplasmic stress responses in Yersinia. Front. Cell. Infect. Microbiol. 2:125. doi: 10.3389/fcimb.2012.00125

Heroven, A. K., Sest, M., Pisano, F., Scheb-Wetzel, M., Steinmann, R., Bohme, K., et al. (2012). Crp induces switching of the CsrB and CsrC RNAs in Yersinia pseudotuberculosis and links nutritional status to virulence. Front. Cell. Infect. Microbiol. 2:158. doi: 10.3389/fcimb.2012.00158

Joseph, S. S., and Plano, G. V. (2013). The SycN/YscB chaperone-binding domain of YopN is required for the calcium-dependent regulation of Yop secretion by Yersinia pestis. Front. Cell. Infect. Microbiol. 3:1. doi: 10.3389/fcimb.2013.00001

Kolodziejek, A. M., Hovde, C. J., and Minnich, S. A. (2012). Yersinia pestis Ail: multiple roles of a single protein. Front. Cell. Infect. Microbiol. 2:103. doi: 10.3389/fcimb.2012.00103

Koornhof, H. J., Smego, R. A. Jr., and Nicol, M. (1999). Yersiniosis. II: the pathogenesis of Yersinia infections. Eur. J. Clin. Microbiol. Infect. Dis. 18, 87-112. doi: 10.1007/s100960050237

Korhonen, T. K., Haiko, J., Laakkonen, L., Jarvinen, H. M., and WesterlundWikstrom, B. (2013). Fibrinolytic and coagulative activities of Yersinia pestis. Front. Cell. Infect. Microbiol. 3:35. doi: 10.3389/fcimb. 2013.00035

Mikula, K. M., Kolodziejczyk, R., and Goldman, A. (2013). Yersinia infection tools-characterization of structure and function of adhesins. Front. Cell. Infect. Microbiol. 2:169. doi: 10.3389/fcimb.2012.00169

Philip, N. H., and Brodsky, I. E. (2012). Cell death programs in Yersinia immunity and pathogenesis. Front. Cell. Infect. Microbiol. 2:149. doi: 10.3389/fcimb.2012.00149

Poncet, S., Milohanic, E., Maze, A., Nait Abdallah, J., Ake, F., Larribe, M., et al. (2009). Correlations between carbon metabolism and virulence in bacteria. Contrib. Microbiol. 16, 88-102. doi: 10.1159/000219374

Rakin, A., Schneider, L., and Podladchikova, O. (2012). Hunger

\section{NEW FRONTIERS}

The systems biology era has revolutionized infectious biology research. Yang et al. (2012) illustrate the power of omics-based explorations in dissecting Yersinia-host cell interplay. In so doing, they provide a perspective on the future of omics-based research in benefitting our understanding of Yersinia cellular physiology and metabolism as well as host cellular responsiveness and immunity.

Finally, manned space exploration demands an evaluation into the effect of such conditions on microbial virulence and infectious disease communicability. Rosenzweig and Chopra (2012) explain that low shear force conditions reduce the virulence capacity of $Y$. pestis. Thus, knowledge of the mechanisms behind these repressive effects could benefit understanding of $Y$. pestis pathogenicity both in space and on earth.

for iron: the alternative siderophore iron scavenging systems in highly virulent Yersinia. Front. Cell. Infect. Microbiol. 2:151. doi: 10.3389/fcimb.2012.00151

Rohmer, L., Hocquet, D., and Miller, S. I. (2011). Are pathogenic bacteria just looking for food? Metabolism and microbial pathogenesis. Trends Microbiol. 19, 341-348. doi: 10.1016/j.tim.2011.04.003

Rosenzweig, J. A., and Chopra, A. K. (2012). The effect of low shear force on the virulence potential of Yersinia pestis: new aspects that space-like growth conditions and the final frontier can teach us about a formidable pathogen. Front. Cell. Infect. Microbiol. 2:107. doi: 10.3389/fcimb.2012.00107

Schiano, C. A., and Lathem, W. W. (2012). Post-transcriptional regulation of gene expression in Yersinia species. Front. Cell. Infect. Microbiol. 2:129. doi 10.3389/fcimb.2012.00129

Smego, R. A., Frean, J., and Koornhof, H. J. (1999). Yersiniosis I: microbiological and clinicoepidemiological aspects of plague and nonplague Yersinia infections. Eur. J. Clin. Microbiol. Infect. Dis. 18, 1-15. doi: 10.1007/s1009600 50219

Uittenbogaard, A. M., Chelvarajan, R. L., Myers-Morales, T., Gorman, A A., Brickey, W. J., Ye, Z., et al. (2012). Toward a molecular pathogenic pathway for Yersinia pestis YopM. Front. Cell. Infect. Microbiol. 2:155. doi: 10.3389/fcimb.2012.00155

Vagima, Y., Levy, Y., Gur, D., Tidhar, A., Aftalion, M., Abramovich,
H., et al. (2012). Early sensing of Yersinia pestis airway infection by bone marrow cells. Front. Cell. Infect. Microbiol. 2:143. doi: 10.3389/fcimb.2012.00143

von Tils, D., Bladel, I., Schmidt, M. A., and Heusipp, G. (2012). Type II secretion in Yersinia-a secretion system for pathogenicity and environmental fitness. Front. Cell. Infect. Microbiol. 2:160. doi: 10.3389/fcimb.2012.00160

Yang, R., Du, Z., Han, Y., Zhou, L., Song, Y., Zhou, D., et al. (2012). Omics strategies for revealing Yersinia pestis virulence. Front. Cell. Infect. Microbiol. 2:157. doi: 10.3389/fcimb.2012.00157

Received: 26 August 2013; accepted: 26 August 2013; published online: 12 September 2013.

Citation: Francis MS (2013) The pathogenic Yersiniae-advances in the understanding of physiology and virulence. Front. Cell. Infect. Microbiol. 3:51. doi: 10.3389/fcimb.2013.00051

This article was submitted to the journal Frontiers in Cellular and Infection Microbiology.

Copyright (c) 2013 Francis. This is an open-access article distributed under the terms of the Creative Commons Attribution License (CC BY). The use, distribution or reproduction in other forums is permitted, provided the original author(s) or licensor are credited and that the original publication in this journal is cited, in accordance with accepted academic practice. No use, distribution or reproduction is permitted which does not comply with these terms. 